\begin{tabular}{|c|c|c|}
\hline 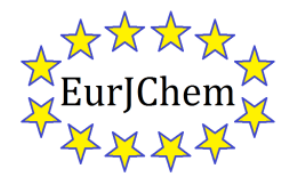 & $\begin{array}{c}\text { European Journal of Chemistry } \\
\text { Journal homepage: } \text { www.eurjchem.com }\end{array}$ & 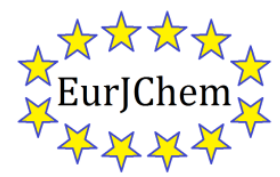 \\
\hline
\end{tabular}

\title{
Synthesis, characterization and luminescence properties of the long afterglow Phosphor $\mathrm{Ba}_{4} \mathrm{Al}_{14} \mathrm{O}_{25}: \mathrm{Eu}$,Dy
}

\author{
Fatih Mehmet Emena,*, Nevzat Külcüb and Ahmet Necmeddin Yazıcı ${ }^{c}$ \\ a Department of Chemistry, Faculty of Arts and Science, Kirklareli University, Kirklareli, TR-39300, Turkey \\ b Department of Chemistry, Faculty of Arts and Science, Mersin University, Mersin, TR-33342, Turkey \\ c Department of Engineering Physics, Gaziantep University, Gaziantep, TR-27310, Turkey
}

${ }^{*}$ Corresponding author at: Department of Chemistry, Faculty of Arts and Science, KIrklareli University, Kirklareli, TR-39300, Turkey. Tel.: +90.505.8712215; fax: +90.288.2129679. E-mail address: femen106@gmail.com (F.M. Emen).

\section{ARTICLE INFORMATION}

Received: 5 January 2010

Received in revised form: 25 January 2010

Accepted: 5 February 2010

Online: 31 March 2010

\section{KEYWORDS}

Phosphorescence

Aluminates

Afterglow

Phosphors

Optical Materials

\begin{abstract}
Long persistent afterglow phosphor, $\mathrm{Ba}_{4} \mathrm{Al}_{14} \mathrm{O}_{25}$ : $\mathrm{Eu}^{2+}$, $\mathrm{Dy}^{3+}$ was prepared at high temperature by a solid state reaction in a weak reductive atmosphere. The crystal structure of $\mathrm{Ba}_{4} \mathrm{Al}_{14} \mathrm{O}_{25}: \mathrm{Eu}^{2+}$, $\mathrm{Dy}^{3+}$ has been determined as an orthorhombic Pmmm space group with $a=18.200(6) \AA, b=16.923(6) \AA, c=5.131(21) \AA, \mathrm{V}=1580.3(9) \AA^{3}$ and $Z=8$. The reflectance measurement was obtained by using the Diffuse Reflectance Spectrophotometer and the band gap energy of the undoped host phase of $\mathrm{Ba}_{4} \mathrm{Al}_{14} \mathrm{O}_{25}$ was calculated by using KubelkaMunk treatment on the diffuse reflectance spectra, and found to be $4.72 \mathrm{eV}$. The excitation and emission peaks are broad bands and the main emission peak at $520 \mathrm{~nm}$ with shoulder at $496 \mathrm{~nm}$ belongs to the intrinsic defect of the host and $4 \mathrm{f}^{6} 5 \mathrm{~d}^{1} \rightarrow 4 \mathrm{f}^{7}$ transition of Eu${ }^{2+}$, respectively. The afterglow decay curve implied that this phosphor contains fast and slowdecay processes. The thermoluminescence glow curve showed one dominant glow peak observed at $50^{\circ} \mathrm{C}$ and two weak glow peaks at around $140{ }^{\circ} \mathrm{C}$ and $220^{\circ} \mathrm{C}$ which are related to the defects at different trap depths.
\end{abstract}

\section{Introduction}

It is often observed that phosphors doped with $\mathrm{Eu}^{2+}$ show rather intense broad photoluminescence (PL) bands with a real short decay time of hundreds of nano seconds. The $\mathrm{Eu}^{2+}$ emission of many phosphor hosts has high enough intensity to find important applications, e.g. in flourescent lamps and plasma displays [1-5]. An important class of phosphors doped with $\mathrm{Eu}^{2+}$ ions is based on alkaline earth aluminates [6]. In 1983, Van Kemenade and Hoeks reported that $\mathrm{Sr}_{4} \mathrm{Al}_{14} \mathrm{O}_{25}: \mathrm{Eu}^{2+}$, Dy ${ }^{3+}$ phosphor had a higher quantum efficiency and better long persistence properties than those of traditional aluminate and sulphide phosphors. There are some articles based on the long afterglow of $\mathrm{Sr}_{4} \mathrm{Al}_{14} \mathrm{O}_{25}: \mathrm{Eu}^{2+}, \mathrm{Dy}^{3+}$ phosphor [7-10]. However, there is no report in the literature on the existence and the luminescence properties of $\mathrm{Ba}_{4} \mathrm{Al}_{14} \mathrm{O}_{25}$ : $\mathrm{Eu}^{2+}, \mathrm{Dy}^{3+}$ compound.

In the present work, we characterized $\mathrm{Ba}_{4} \mathrm{Al}_{14} \mathrm{O}_{25}: \mathrm{Eu}^{2+}$,Dy ${ }^{3+}$ phosphor which was prepared by using traditional solid state reaction method. The photoluminescence and thermoluminescence properties and long lasting phosphorescence mechanism of this phosphor were investigated systematically.

\section{Experimental}

\subsection{Synthesis}

The $\mathrm{Ba}_{4} \mathrm{Al}_{14} \mathrm{O}_{25}: \mathrm{Eu}^{2+}, \mathrm{Dy}^{3+}$ phosphor was prepared by solidstate reaction method involving $\mathrm{BaCO}_{3}, \mathrm{Al}(\mathrm{OH})_{3}, \mathrm{Eu}_{2} \mathrm{O}_{3}$ and $\mathrm{Dy}_{2} \mathrm{O}_{3}$ as the starting materials. A small amount of $\mathrm{H}_{3} \mathrm{BO}_{3}$ was added to the mixture as a flux. We weighed the components of the powder as it is in the nominal composition of $4 \mathrm{BaO}+(7-$ x) $\mathrm{Al}_{2} \mathrm{O}_{3}+\mathrm{xB}_{2} \mathrm{O}_{3}$ with $1 \% \mathrm{Eu}_{2} \mathrm{O}_{3}$ and $2 \% \mathrm{Dy}_{2} \mathrm{O}_{3}$ and thoroughly mixed and grounded it with a ballmill. The mixed powder was placed into a platinum-lined boat and prefired at $1000{ }^{\circ} \mathrm{C}$ for 4 $\mathrm{h}$ for the initial decomposition reaction. Then, the powder was re-grounded and sintered at $1300{ }^{\circ} \mathrm{C}$ for $7 \mathrm{~h}$ in reducing atmosphere $\left(\mathrm{N}_{2}, 90 \%+\mathrm{H}_{2}, 10 \%\right)$. The sintered powder was grounded again and washed by using boiling acetic acid solution to remove amorf barium borate phases.

\subsection{Instrumentation}

The structural phase identification of products were carried out by X-ray powder diffraction (XRD) (Bruker, AXS, East Cheryl Parkway, USA) with $\mathrm{CuK} \alpha(\lambda=1.54 \AA)$ radiation. Infrared spectrum (FT-IR) was recorded on a FT-IR Spectrometer (Mattson Satellite 3000, Thermo Electron Corporation, Erlangen, Germany) in the range of 4000-400 $\mathrm{cm}^{-1}$ by dispersing the sample in anhydrous $\mathrm{KBr}$ pellets. A TG/DTA combined system (Shimadzu DTG-60H, Tokyo, Japan) was used to determine the reaction conditions in the temperature range of $25-1450{ }^{\circ} \mathrm{C}$ under inert $\mathrm{N}_{2}$ atmosphere with flow rate of 10 $\mathrm{mL} / \mathrm{min}$. The diffuse reflectance measurement was carried out by using UV-Vis Spectrophotometer (Varian, Cary 100 Bio, Victoria, Australia) with DRA-CA-301 Diffuse Reflectance Accessory at room temperature (RT) in the wavelenght range of 200-800 nm. Photoluminescence (PL) spectra were obtained at RT by using a Flourescence Spectrophotometer (Warian, Cary Eclipse, Victoria, Australia). The thermo luminescence (TL) glow curve of $\mathrm{Ba}_{4} \mathrm{Al}_{14} \mathrm{O}_{25}: \mathrm{Eu}^{2+}$, $\mathrm{Dy}^{3+}$ was measured by using a TL reader (Harshaw-QS 3500, Erlangen, Germany) at linear 
heating rate of $1{ }^{\circ} \mathrm{C} / \mathrm{s}$ after irradiation using a ${ }^{0} \mathrm{Sr} /{ }^{90} \mathrm{Y} \beta$-source $(2.2 \mathrm{MeV})$ at a dose rate of approximately $0.04 \mathrm{~Gy} / \mathrm{s}$ at RT.

\section{Results and Discussion}

The DTA/TG curves of the starting materials are given in Figure 1. It seems that a weak endothermic peak between 30 $214{ }^{\circ} \mathrm{C}$ with a $0.6 \%$ weight loss which belongs to the decomposition of boric acid. The three other endothermic peaks in DTA diagram at 240,297 and $529{ }^{\circ} \mathrm{C}$ correspond to three different decomposition steps of $\mathrm{Al}(\mathrm{OH})_{3}$ in TG diagram with weight losses of $2.8 \%, 13.4 \%$ and $3.7 \%$, respectively. The exothermic peak at $1000{ }^{\circ} \mathrm{C}$ corresponds to the decomposition of $\mathrm{BaCO}_{3}$ to $\mathrm{BaO}$ which reacts with $\mathrm{Al}_{2} \mathrm{O}_{3}$ and $\mathrm{B}_{2} \mathrm{O}_{3}$ to yield $\mathrm{Ba}_{4} \mathrm{Al}_{14} \mathrm{O}_{25}$.

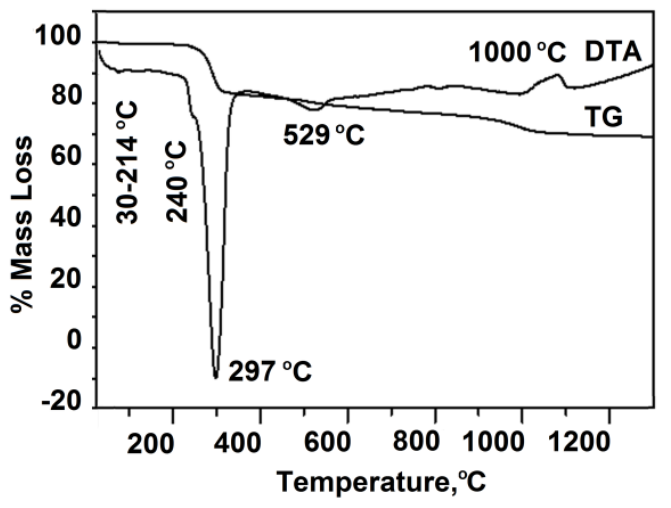

Figure 1. DTA-TG curves of starting materials.

The XRD patterns of $\mathrm{Ba}_{4} \mathrm{Al}_{14} \mathrm{O}_{25}: \mathrm{Eu}^{2+}, \mathrm{Dy}^{3+}$ calcined at 1300 ${ }^{\circ} \mathrm{C}$ are shown in Figure 2. The crystal structure of the sample is refined by using the WinxPow software [11]. The pattern can be indexed as a single phase having orthorhombic crystal system with $P m m m$ space group with unit cell parameters of $a=18.200(6) \AA, b=16.923(6) \AA, c=5.131(21) \AA$ and with a volume of $\mathrm{V}=1580.3(9) \AA^{3}, Z=8$. $\mathrm{Ba}_{4} \mathrm{Al}_{14} \mathrm{O}_{25}$, has the same crystall structure as $\mathrm{Sr}_{4} \mathrm{Al}_{14} \mathrm{O}_{25}$ which has a chain structure made of $\mathrm{AlO}_{6}$ octahedra, but strontium ions are sited in the cavities of the $\mathrm{AlO}_{4}$ tetrahedra [12].

The Infrared (FT-IR) Spectrum of $\mathrm{Ba}_{4} \mathrm{Al}_{14} \mathrm{O}_{25}: \mathrm{Eu}^{2+}, \mathrm{Dy}^{3+}$ phase is shown in Figure 3. The band which is observed in the infrared spectrum can be attributed to symmetric stretching at $\gamma_{\mathrm{s}}(\mathrm{Al}-0)=688 \mathrm{~cm}^{-1}$, symmetric bending $\delta_{\mathrm{s}}(0-\mathrm{Al}-0)=495 \mathrm{~cm}^{-1}$, antisymmetric stretching $\gamma_{\text {as }}(\mathrm{Al}-\mathrm{O})=770-990 \mathrm{~cm}^{-1}$ and antisymmetric bending $\delta_{\mathrm{d}}(\mathrm{O}-\mathrm{Al}-0)=520-678 \mathrm{~cm}^{-1}$ of $\mathrm{AlO}_{4}$ groups in $\mathrm{Ba}_{4} \mathrm{Al}_{14} \mathrm{O}_{25}$. The absorption band at $1050 \mathrm{~cm}^{-1}$ is assigned to $\mathrm{B}-\mathrm{O}$ stretching vibration of tetrahedral $\mathrm{BO}_{4}$ units.

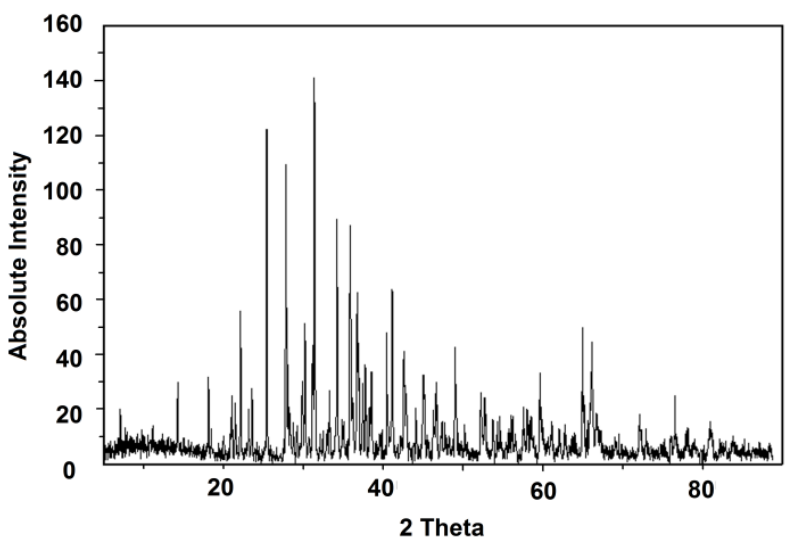

Figure 2. The XRD pattern of $\mathrm{Ba}_{4} \mathrm{Al}_{14} \mathrm{O}_{25}: \mathrm{Eu}^{2+}, \mathrm{Dy}^{3+}$ phase was calcined at $1300^{\circ} \mathrm{C}$.

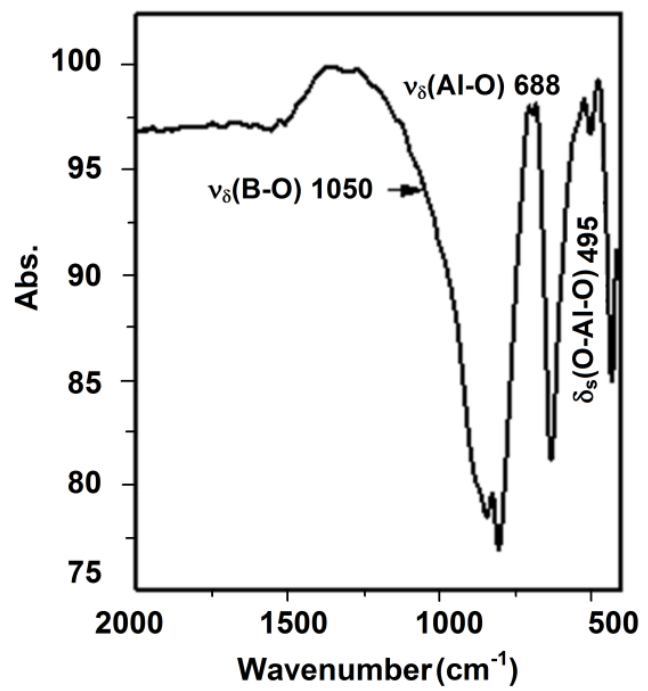

Figure 3. Infrared absorption spectra of $\mathrm{Ba}_{4} \mathrm{Al}_{14} \mathrm{O}_{25}: \mathrm{Eu}^{2+}, \mathrm{Dy}{ }^{3+}$ phosphor.

This indicates the presence of substitutional boron in $\mathrm{AlO}_{4}$ framework as $\mathrm{Ba}_{4} \mathrm{Al}_{14-\mathrm{x}} \mathrm{B}_{\mathrm{x}} \mathrm{O}_{25}$. When $\mathrm{B}_{2} \mathrm{O}_{3}$ was added as a flux, $\mathrm{BO}_{4}$ took place in the formation of structural units by breaking off the O-Al-O-Al-O bonds in the aluminate framework and forms O-Al-O-B-O bonds [13].

The diffuse reflectance spectra of undoped $\mathrm{Ba}_{4} \mathrm{Al}_{14} \mathrm{O}_{25}$ is given in Figure 4. The broad band observed around $254 \mathrm{~nm}$ is due to the absorption across the band gap of the host matrix.

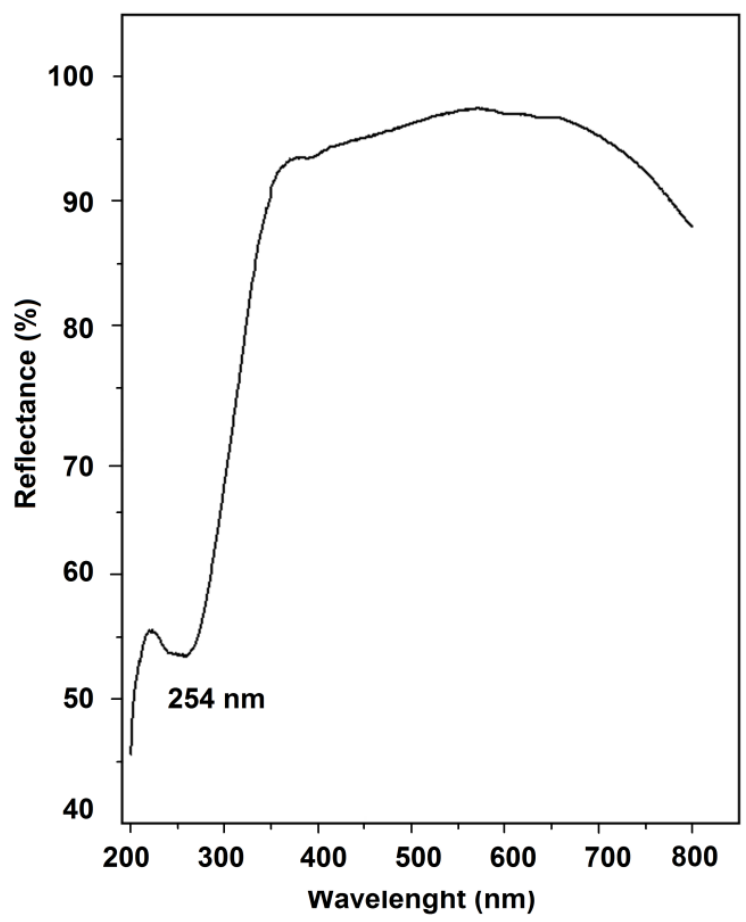

Figure 4. The diffuse reflectance spectra of $\mathrm{Ba}_{4} \mathrm{Al}_{14} \mathrm{O}_{25}$ host matrix.

The diffuse reflectance spectra of the undoped $\mathrm{Ba}_{4} \mathrm{Al}_{14} \mathrm{O}_{25}$ was transformed by performing the Kubelka-Munk transformation of the measured reflectance according to the following equation;

$\mathrm{K}=(1-\mathrm{R})^{2} / 2 \mathrm{R}=\mathrm{F}(\mathrm{R})$ 
where $\mathrm{K}$ is reflectance transformed according to KubelkaMunk, $\mathrm{R}$ is reflectancy (\%), and $\mathrm{F}(\mathrm{R})$ is the so-called remission or Kubelka-Munk function [14-15].

It is well known that the band gap $\mathrm{Eg}_{\mathrm{g}}$ and the absorption coefficient $\alpha$ are related as in follwing equation;

$\alpha \mathrm{h} v=A(\mathrm{~h} v-\mathrm{Eg})^{1 / 2}$

where $A$ is a constant [16-19]. If the compound scatters in a perfectly diffuse manner, $\mathrm{K}$ becomes equal to $2 \alpha$. In this case, we can use the following expression;

$$
[\mathrm{F}(\mathrm{R}) \mathrm{h} v]^{2}=A\left(\mathrm{~h} v-\mathrm{Eg}_{\mathrm{g}}\right)
$$

The band gap $\mathrm{E}_{\mathrm{g}}$ of a powdered sample can be obtained easily from the $[F(R) h v]^{2}$ versus $h v$ plot.

The $[\mathrm{F}(\mathrm{R}) \mathrm{h} v]^{2}$ versus $\mathrm{h} v$ graph of $\mathrm{Ba}_{4} \mathrm{Al}_{14} \mathrm{O}_{25}$ is presented in Figure 5 . The band gap energy is obtained by extrapolating the straight portion of the curve to the $h v$ axis. The band gap value thus obtained turned out to be $4.72 \mathrm{eV}$.

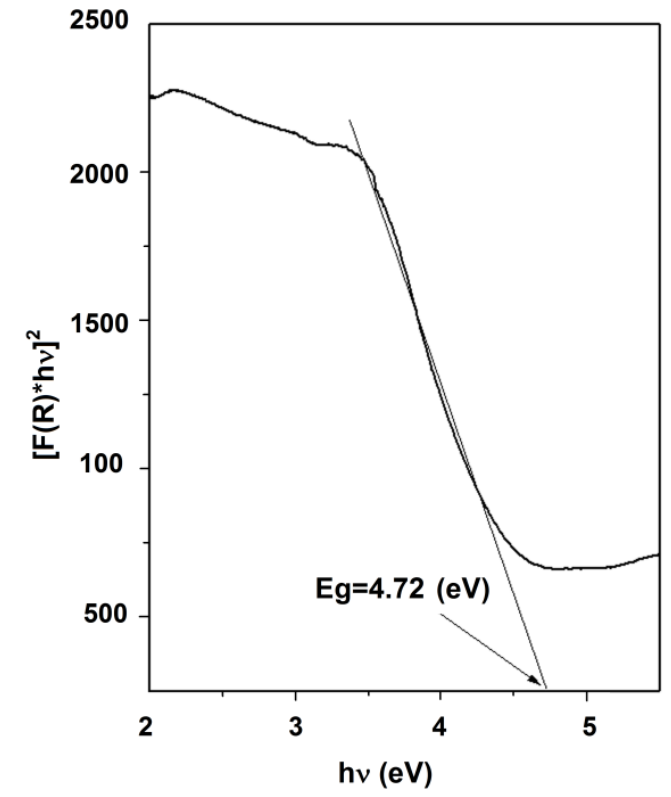

Figure 5. $\alpha 2$ versus hv graph of the undoped $\mathrm{Ba}_{4} \mathrm{Al}_{14} \mathrm{O}_{25}$ phase.

The photoluminescence curves of undoped host phase, $\mathrm{Ba}_{4} \mathrm{Al}_{14} \mathrm{O}_{25}$ and doped phase, $\mathrm{Ba}_{4} \mathrm{Al}_{14} \mathrm{O}_{25}: \mathrm{Eu}^{2+}, \mathrm{Dy}^{3+}$ are shown in Figure 6 and 7 , respectively. The host phase shows red emission that has short lifetime, under $254 \mathrm{~nm}$ UV lamp. After excitation of undoped phase at $257 \mathrm{~nm}$, it reveals two emission bands; one of them is a sharp band at $520 \mathrm{~nm}$ and the other one is a broad band in the range of $650-850 \mathrm{~nm}$. The broad band emission of the host is probably due to the intrinsic defect in the host material. It is known that the crystallization process and the flux added can cause defects, which trap electrons and holes [20].

The emission spectrum of $\mathrm{Ba}_{4} \mathrm{Al}_{14} \mathrm{O}_{25}: \mathrm{Eu}^{2+}, \mathrm{Dy}^{3+}$ shows two broad bands around $520 \mathrm{~nm}$ with a shoulder at $496 \mathrm{~nm}$ and $650-850 \mathrm{~nm}$ range after excitation by $257 \mathrm{~nm}$. The same results are obtained in the absence of rare-earth activators $\mathrm{Cu}^{2+}$ and $\left.\mathrm{Dy}^{3+}\right)$. But, the $\mathrm{Eu}^{2+}$ and $\mathrm{Dy}^{3+}$ co-doped phosphor shows blue emission with long lasting phosphorescence. It is known that the emission of $\mathrm{Eu}^{2+}$ ion in the crystalline phase generally shows a broad emission band due to $4 \mathrm{f}^{6} 5 \mathrm{~d}^{1} \rightarrow 4 \mathrm{f}^{7}$ transition, on the other hand $\mathrm{Eu}^{3+}$ ion gives a series of typical emission lines in the spectral region of $570-750 \mathrm{~nm}$ which correspond to ${ }^{5} D_{0} \rightarrow{ }^{7} F_{j}(j=0-4)$ transitions. It can be seen in Figure 7 that there is a broad band around $520 \mathrm{~nm}$ with a shoulder at $496 \mathrm{~nm}$. The blue-green emission can be attributed to the interaction between the host crystal lattice and activator ions $\mathrm{Eu}^{2+}$. The emission band at $520 \mathrm{~nm}$ observed in $\mathrm{Ba}_{4} \mathrm{Al}_{14} \mathrm{O}_{25}$ host matrix and $\mathrm{Ba}_{4} \mathrm{Al}_{14} \mathrm{O}_{25}: \mathrm{Eu}^{2+}, \mathrm{Dy}^{3+}$ phosphor indicate that the emission is due to the native defect in the host crystal such as cation or anion vacancies. These traps in the doped phase may be created during the process of the incorporation of the activator (Eu) and co-activator (Dy) atoms. It must be mentioned that the intensity of the emission band at $520 \mathrm{~nm}$ of doped phase increased compared to the undoped phases. On the other hand, the band intensity between $650-850 \mathrm{~nm}$ of the doped phase decreased relative to the undoped phases.

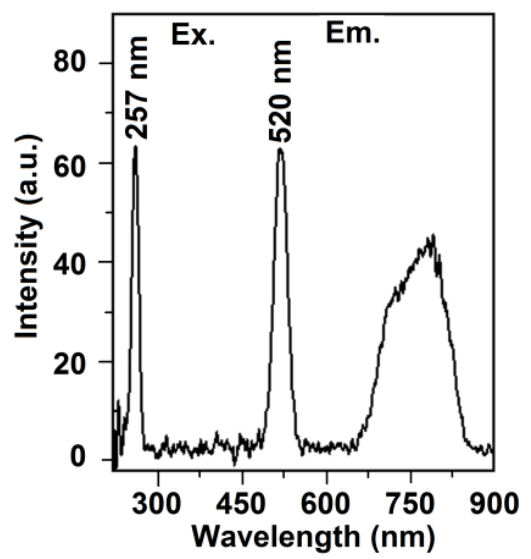

Figure 6. The photoluminescence curves of undoped phase, $\mathrm{Ba}_{4} \mathrm{Al}_{14} \mathrm{O}_{25}$

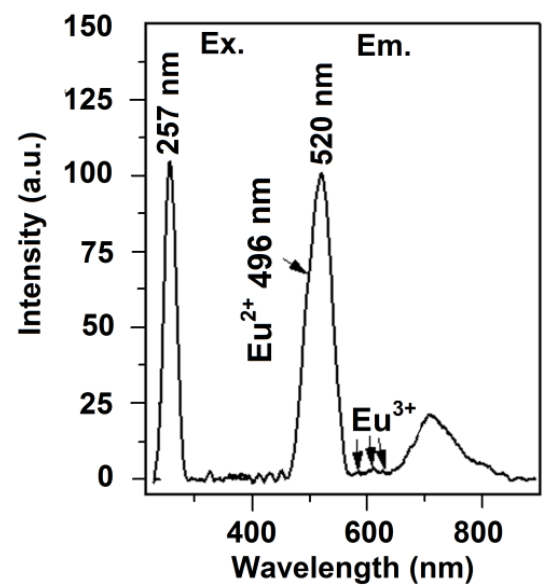

Figure 7. The photoluminescence curves of doped phase, $\mathrm{Ba}_{4} \mathrm{Al}_{14} \mathrm{O}_{25}: \mathrm{Eu}^{2+}, \mathrm{Dy}^{3+}$.

The afterglow decay curve of $\mathrm{Ba}_{4} \mathrm{Al}_{14} \mathrm{O}_{25}: \mathrm{Eu}^{2+}, \mathrm{Dy}^{3+}$ phosphor is shown in Figure 8. The afterglow decay curve was measured by $496 \mathrm{~nm}$ emission wavelength intensity. The afterglow decay time had been analyzed by a curve fitting technique based on the following multiple equation:

$I=A_{1} \exp \left(-t / \tau_{1}\right)+A_{2} \exp \left(-t / \tau_{2}\right)+A_{3} \exp \left(-t / \tau_{3}\right)$

where $I$ is phosphorescence intensity, $A_{1}, A_{2}$ and $A_{3}$ are constants, $t$ is the time, $\tau_{1}, \tau_{2}$ and $\tau_{3}$ are afterglow decay times for the exponential components, respectively [21-22]. Using the fitting function provided by ORIGIN61 software, the calculated afterglow decay times for the mentioned compounds were found as $\tau_{1}=9.60 \mathrm{~min}, \tau_{2}=12.06 \mathrm{~min}$ and $\tau_{3}=15.19 \mathrm{~min}$, respectively. We can conclude that $4 \mathrm{f}^{\mathrm{n}-1} 5 \mathrm{~d}^{1} \rightarrow 4 \mathrm{f}^{\mathrm{n}}$ transition in $\mathrm{Ba}_{4} \mathrm{Al}_{14} \mathrm{O}_{25}: \mathrm{Eu}^{2+}$, $\mathrm{Dy}^{3+}$ phosphor corresponds to a long afterglow which is caused by the energy processes between traps and activators, in this case $\mathrm{Eu}^{2+}$ and $\mathrm{Dy}^{3+}$. The phosphor exhibits a long afterglow over $5 \mathrm{~h}$ which is recognizable to the naked eye in the dark after the exciting source is removed. 


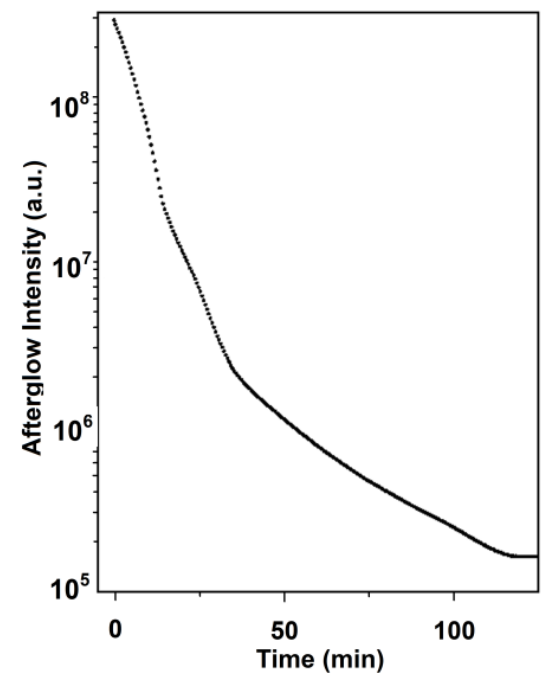

Figure 8. Decay curve of $\mathrm{Ba}_{4} \mathrm{Al}_{14} \mathrm{O}_{25}: \mathrm{Eu}^{2+}, \mathrm{Dy}^{3+}$ phosphor.

The decay time characteristic of a phosphor material mainly depends on the kinetic parameters $\left(E, s, b\right.$ and $\left.n_{o}\right)$ describing the trapping-emitting centers which is quantitatively responsible for the TL emission. For example, the estimation of the time elapsed since exposure is closely related to the position of the trapping levels $(E)$ within the band gap and frequency factor $(s)$ of the electrons in the traps, and therefore it is necessary to have a good knowledge of these parameters. There are various methods for evaluating the trapping parameters from TL glow curves [23]. For example, when one of the glow peaks is highly isolated from the others, the experimental method such as peak shape method is a suitable method to determine them from the glow peak. However, in most materials such as $\mathrm{Ba}_{4} \mathrm{Al}_{14} \mathrm{O}_{25}: \mathrm{Eu}^{2+}$,Dy ${ }^{3+}$ the glow curve of $\mathrm{Ba}_{4} \mathrm{Al}_{14} \mathrm{O}_{25}: \mathrm{Eu}^{2+}, \mathrm{Dy}^{3+}$ consists of several overlapping glow peaks. When more than one glow peak is present in a glow curve, there are essentially two ways to obtain these parameters: the first is to isolate each individual TL peak from the others using partial thermal annealing treatment and the other one is to make a complete glow curve analysis using deconvolution [23]. Therefore, the peak shape method along with the deconvolution method has been used to analyze the glow curves of $\mathrm{Ba}_{4} \mathrm{Al}_{14} \mathrm{O}_{25}$ : $\mathrm{Eu}^{2+}, \mathrm{Dy}^{3+}$ in the present study. The recorded glow curve of $\mathrm{Ba}_{4} \mathrm{Al}_{14} \mathrm{O}_{25}: \mathrm{Eu}^{2+}, \mathrm{Dy}^{3+}$ was first analyzed using a curve fitting program [23]. When the glow curves were analyzed by this program, the information on the number of glow peaks present in the glow curve and their kinetic parameters can be easily obtained. In this program, the TL glow curves were analyzed by using the following approximate solution of the general-order kinetics of the TL;

$I(T)=n_{0} s \exp \left(-\frac{E}{k T}\right)\left[1+\frac{(b-1) s}{\beta} \frac{k T^{2}}{E} \exp \left(-\frac{E}{k T}\right) *\left(0.992-1.620 \frac{k T}{E}\right)\right]^{\frac{b}{1-b}}$

where $n_{0}\left(\mathrm{~m}^{-3}\right)$ is the concentration of trapped electrons at $t=0$, $T(\mathrm{~K})$ is the absolute temperature, $k\left(\mathrm{eVK}^{-1}\right)$ is Boltzmann's constant, $s\left(\mathrm{~s}^{-1}\right)$ is frequency factor, $\beta(\mathrm{K} / \mathrm{s})$ is heating rate, $b$ is the kinetic order, and $E(\mathrm{eV})$ is the activation energy (trap depth). The goodness of fitting for all of the measured glow curves was tested using the figure of merit (FOM) [24-25]. It is known that if the FOM values are between $0.0 \%$ and $2.5 \%$ the fit is good, between $2.5 \%$ and $3.5 \%$ it is a fair fit, and $>3.5 \%$ it is a bad fit. Figure 9 shows one of the analyzed glow curves of $\mathrm{Ba}_{4} \mathrm{Al}_{14} \mathrm{O}_{25}: \mathrm{Eu}^{2+}$,Dy ${ }^{3+}$ phosphor after irradiating the sample for 5 min $(\approx 12$ Gy) by $\beta$-rays. As can be seen clearly, the TL glow curves of this phosphor exhibit three TL glow peaks at about 50,140 and $220^{\circ} \mathrm{C}$ when heated at a constant heating rate of 1
${ }^{\circ} \mathrm{C} / \mathrm{s}$. The obtained kinetic parameters by this method were given in the inset of Figure 9.

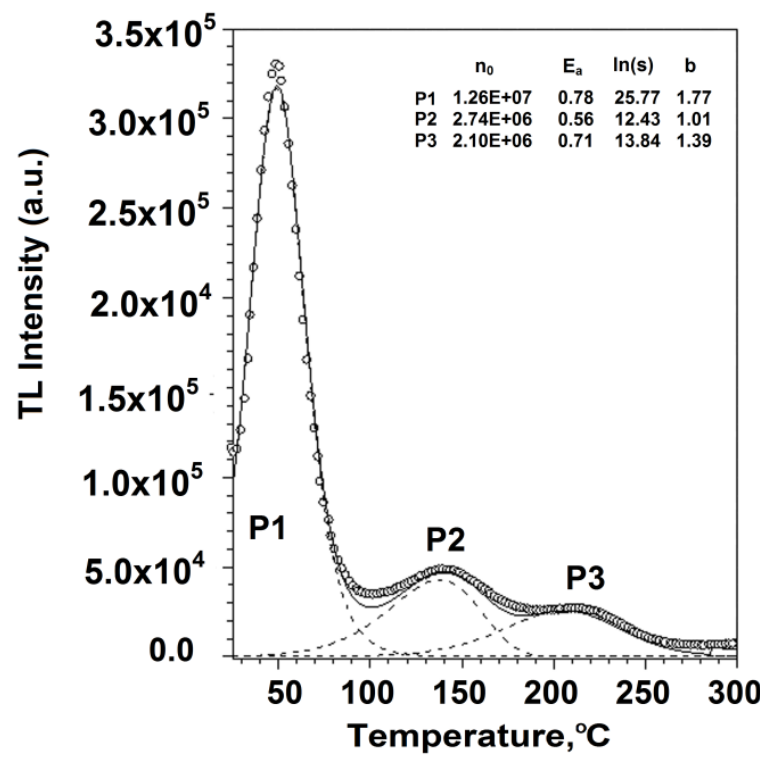

Figure 9. An analyzed glow curve of $\mathrm{Ba}_{4} \mathrm{Al}_{14} \mathrm{O}_{25}$ : $\mathrm{Eu}^{2+}, \mathrm{Dy}^{3+}$ obtained at a heating rate of $1{ }^{\circ} \mathrm{C} / \mathrm{s}$ following $\beta$-ray exposure at room temperature $(\mathrm{D} \approx 12$ Gy). The open circles represent the experimental points, the full curve is the global fitting and broken curves represent fitted individual glow peaks.

As mentioned previously, if one glow peak is highly isolated from the others, the peak shape method is a suitable method to determine the kinetic parameters. In this respect, the peak 1 is highly isolated from the others and therefore in addition to the deconvolution method, the data of glow curves were also used to determine the kinetic parameters of peak 1 by the peak shape method. This method is based on the shape and fullwidth at half maximum (FWHM $=T_{2}-T_{1}$ ) of a single glow peak and the values of trap depth were determined by the modified peak shape method of Chen [26]. According to this method, the kinetic order of a single glow peak is easily obtained by means of the geometric factor $\left\{\mu_{g}=\left(T_{2}-T_{m}\right) /\left(T_{2}-T_{1}\right)\right\}$ and $\mu_{g}$ changes with the order of kinetics from $\approx 0.42$ to $\approx 0.52$, where these two limits correspond to first- and second-order kinetics, respectively. The trap depth $E$ is calculated from the peak parameters by the following equations $[23,26,27]$;

$E_{\tau}=\left[1.51+3\left(\mu_{g}-0.42\right)\right] \frac{k T_{m}^{2}}{\tau}-\left[1.58+4.2\left(\mu_{g}-0.42\right)\right] 2 k T_{m}$

$E_{\delta}=\left[0.976+7.3\left(\mu_{g}-0.42\right)\right] \frac{k T_{m}^{2}}{\delta}$

$E_{\omega}=\left[2.52+10.2\left(\mu_{g}-0.42\right)\right] \frac{k T_{m}^{2}}{\omega}-2 k T_{m}$

where $T_{m}$ is the peak temperature, $\omega=T_{2}-T_{1}$ is the full width at half-maximum, $\delta=T_{2}-T_{m}$ is the half width on the high temperature side of the maximum, $\tau=T_{m}-T_{1}$ is the half width on the low-temperature side of the maximum, and $\mu_{g}=\delta / \omega$ is the geometric factor (peak-shape parameter). After determination of the trap depth and the order of kinetics, the frequency factor $s$, in general, can be estimated using the relation

$s=\left[\frac{k T_{m}^{2}}{\beta E} \exp \left(-\frac{E}{k T_{m}}\right)\left(1+(b-1) \frac{2 k T_{m}}{E}\right)\right]^{-1}$ 
The calculated kinetic parameters of peak 1 of $\mathrm{Ba}_{4} \mathrm{Al}_{14} \mathrm{O}_{25}: \mathrm{Eu}^{2+}$,Dy ${ }^{3+}$ phosphor by the peak shape method are given in Table.1.

Table.1. The kinetic parameters of peak 1 of $\mathrm{Ba}_{4} \mathrm{Al}_{14} \mathrm{O}_{25}: \mathrm{Eu}^{2+}, \mathrm{Dy}^{3+}$ phosphor calculated by the peak shape method.

\begin{tabular}{|c|c|c|c|c|c|c|}
\hline \multirow{2}{*}{$\begin{array}{l}\text { Peak } \\
\text { Temp. } \\
T_{m}(\mathrm{~K})\end{array}$} & \multirow{2}{*}{$\begin{array}{c}\text { Geometric } \\
\text { Factor } \\
(\mu)\end{array}$} & \multirow{2}{*}{$\begin{array}{l}\text { Kinetic } \\
\text { Order } \\
\text { (b) }\end{array}$} & \multicolumn{3}{|c|}{$\begin{array}{c}\text { Activation Energy } \\
(E(\mathrm{eV}))\end{array}$} & \multirow{2}{*}{$\begin{array}{c}\text { Freq. } \\
\text { Factor } \\
\left(s\left(s^{-1}\right)\right)\end{array}$} \\
\hline & & & $\boldsymbol{E}_{\tau}$ & $\boldsymbol{E}_{\delta}$ & $\boldsymbol{E}_{\boldsymbol{\omega}}$ & \\
\hline 323 & 0.506 & $\approx 1.8$ & 0.90 & 0.89 & 0.90 & $1.0 \times 10^{12}$ \\
\hline
\end{tabular}

It is obvious that the higher the trap concentration the longer the afterglow because of the capturing of more free electrons that are excited by UV or ionizing irradiation. Morover, another important factor for a long lasting phosphor is to produce a suitable trap depth within the host. If the trap depth is too low, the electrons in the trap can return to the energy level of the excited state easily, thus resulting in a short afterglow lifetime. On the other hand, if the trap depth is too deep, the transition probability of electrons in the traps to the excited state is very low. In such a state, the afterglowing is less intense. According to Sakai's report, a trap depth between 0.6$0.7 \mathrm{eV}$ is suitable for a long afterglow [28]. The frequency factor is also another important parameter that affects the lifetime of electrons in the traps. In this case, when the frequency factor is increased, the lifetime of the electrons in the traps is decreased. As a result, $\mathrm{Ba}_{4} \mathrm{Al}_{14} \mathrm{O}_{25}: \mathrm{Eu}^{2+}, \mathrm{Dy}^{3+}$ phosphor with a trap depth higher than $0.75 \mathrm{eV}$, a frequency factor less than $1.0 \times 10^{12} \mathrm{~s}^{-1}$ and a trap concentration greater than $1.0 \times 10^{7} \mathrm{~cm}^{-3}$ exhibits a long afterglow over $5 \mathrm{~h}$.

The scheme in the Figure 10 shows long persistent mechanism based on Dorenbos model [29]. When the phosphor is excited by UV light, the electrons escape from $\mathrm{Eu}^{2+}$ to the conduction band of $\mathrm{Ba}_{4} \mathrm{Al}_{14} \mathrm{O}_{25}$ and $\mathrm{Eu}^{2+}$ will be converted to $\mathrm{Eu}^{3+}$. The escaped electrons are trapped by $\mathrm{Dy}^{3+}$ to create $\mathrm{Dy}^{2+}$. After the excitation resource is removed, a slow thermal release of the electrons followed by re-trapping on $\mathrm{Eu}$ and thus creating a $4 \mathrm{f}^{6} 5 \mathrm{~d}^{1} \rightarrow 4 \mathrm{f}^{7}$ emission which causes a long persistent luminescence.

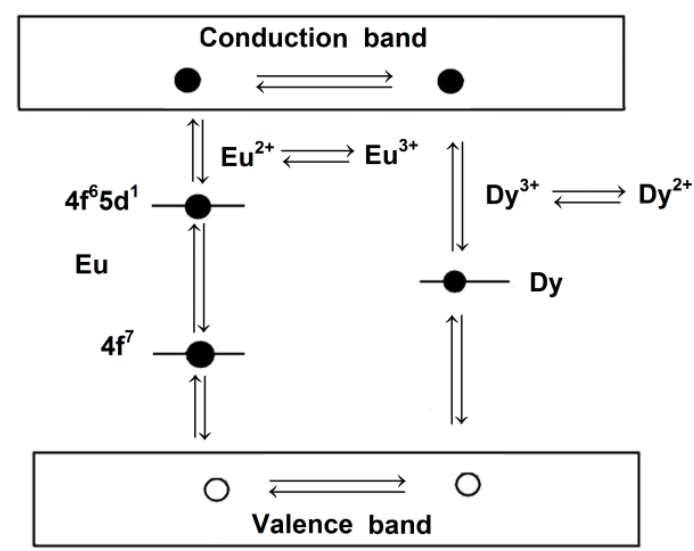

Figure 10. The long persistent mechanism of $\mathrm{Ba}_{4} \mathrm{Al}_{14} \mathrm{O}_{25}: \mathrm{Eu}^{2+}, \mathrm{Dy}^{3+}$

\section{Conclusions}

Long afterglow $\mathrm{Ba}_{4} \mathrm{Al}_{14} \mathrm{O}_{25}: \mathrm{Eu}^{2+}, \mathrm{Dy}^{3+}$ phosphor was synthesized by using solid state reaction method. The diffuse reflectance measurement was obtained by using the Diffuse Reflectance Spectrophotometer and the band gap energy $\left(E_{g}\right)$ of the undoped host phase, $\mathrm{Ba}_{4} \mathrm{Al}_{14} \mathrm{O}_{25}$ was calculated from the absorption spectra as $4.72 \mathrm{eV}$. While undoped $\mathrm{Ba}_{4} \mathrm{Al}_{14} \mathrm{O}_{25}$ shows two emission bands centered about 520 and $650-850 \mathrm{~nm}$, $\mathrm{Ba}_{4} \mathrm{Al}_{14} \mathrm{O}_{25}: \mathrm{Eu}^{2+}$,Dy ${ }^{3+}$ shows two bands at $520 \mathrm{~nm}$ with shoulder at $496 \mathrm{~nm}$ and a broad band in the range of $650-850 \mathrm{~nm}$. The emission bands for the host is probably due to the intrinsic defect of the host. It's possible that the emission band at 496 $\mathrm{nm}$ can be attributed to the transition of $4 \mathrm{f}^{6} 5 \mathrm{~d}^{1} \rightarrow 4 \mathrm{f}^{7}$ in $\mathrm{Eu}^{2+}$. The thermoluminescence glow curve shows one dominant glow peak at $50^{\circ} \mathrm{C}$ and two weak glow peaks at around 140 and 220 ${ }^{\circ} \mathrm{C}$, respectively. The kinetic parameters were calculated by glow curve deconvolution and peak shape methods. $\mathrm{Ba}_{4} \mathrm{Al}_{14} \mathrm{O}_{25}: \mathrm{Eu}^{2+}$,Dy ${ }^{3+}$ phosphor with a trap depth higher than $0.75 \mathrm{eV}$, a frequency factor less than $1 \times 10^{12} \mathrm{~s}^{-1}$ and a trap concentration greater than $1.0 \times 10^{7} \mathrm{~cm}^{-3}$ exhibits a long afterglow over $5 \mathrm{~h}$. Also, long after glowing mechanism was discussed based on the Dorenbos model. If the phosphor is excited by UV light, the electrons escap from $\mathrm{Eu}^{2+}$ to the conduction band of $\mathrm{Ba}_{4} \mathrm{Al}_{14} \mathrm{O}_{25}$ and $\mathrm{Eu}^{2+}$ will be converted to $\mathrm{Eu}^{3+}$. The escaped electrons are trapped by Dy ${ }^{3+}$ to create $\mathrm{Dy}^{2+}$. After the excitation, if the exitation source is removed, a slow thermal release of the electrons followed by re-trapping on Eu and thus creating a $4 \mathrm{f}^{6} 5 \mathrm{~d}^{1} \rightarrow 4 \mathrm{f}^{7}$ emission which cause a long persistent luminescence.

\section{Acknowledgement}

The authors would like to thank to Dr. Hulya Metin (from Mersin University) and M.Sc. Physicist Selma Erat (from EMPA, Switzerland) for their helpful discussions on the optical properties and also Res. Ass. Vural E. Kafadar (Gaziantep University) for his help to calculate the TL kinetic parameters using a curve fitting program. This work was financially supported by TUBITAK (107T392) and Mersin University research found (BAP-FBE KB (FME) 2006-2 D).

\section{References}

[1]. Kenyon A. J.; Chryssou C. E.; Pitt C. W.; Iwayama T. S.; Hole D. E.; Sharma N.; Humphreys C. J. J. Appl. Phys., 2002, 91, 367-374.

[2]. Schmechel R.; Kennedy M.; Seggern H. V.; Winkler H.; Kolbe M.; Fischer R. A.; Li X. M.; Benker A.; Winterer M.; Hahn H. J. Appl. Phys. 2001, 89 1679-1686.

[3]. Wakefield G.; Holland E.; Dobson P. J.; Hutchison J. L. Adv. Mater. 2001, $13,1557-1560$

[4]. Li Q.; Gao L.; Yan D. S. Chem. Mater. 1999, 11, 533-535.

[5]. Bartko A. P.; Peyser L. A.; Dickson R. M.; Mehta A.; Thundat T.; Bhargava R.; Barnes M. D.; Chem. Phys. Lett. 2002, 358, 459-465.

[6]. Wang D.; Wang M.; Lu G. J. Mater. Sci. 1999, 34, 4959-4964.

[7]. Nag A.; Kutty T. R. N. J. Alloys Comp. 2003, 354, 221-31.

[8]. Peng M.; Pei Z.; Hong G.; Su Q. Chem. Phys. Lett. 2003, 371, 1-6.

[9]. Yuan Z. X.; Chang C. K.; Mao D. L.; Ying W. J. Alloys Compd., 2004, 377 268-268.

[10]. Chang C.; Yuan Z.; Mao D. J. Alloys Compd. 2006, 415, 220-224.

[11]. Eremina E. A.; Chekanova A. E.; Kazin A. P.; Rumyantseva M. N.; Kazin P. E.; Tret'yakov Y. D. Inorg. Mater. 2007, 43, 853-859.

[12]. Nadzhina T. N.; Pobedimskaya E. A.; Belov N. V.; Kristallografiya 1980 $25,938-943$

[13]. Nag A.; Kutty T. R. N. Mater. Res. Bull. 2004, 39, 331-42 (2004)

[14]. Morales A. E.; Mora E. S.; Pal U. Revista Mecsicana De Fisica S, 2007, 53, 18-22.

[15]. Zhou F.; Kang K.; Maxisch T.; Ceder G.; Morgan D. Solid State Commun 2004, 132, 181-186.

[16]. Pankove J. N., Absorption, Dover Puplications, Inc. New York, 1975.

[17]. Erat S.; Metin H.; Arı M. Mater. Chem. Phys. 2008, 111, 114-120.

[18]. Oladeji O. I.; Chow L.; Thin Solid Films, 2005, 474, 77-83.

[19]. Maity R.; Chatopadhyay K. K. J. Nanopart. Res., 2006, 8, 125-130.

[20]. Ropp R. C. The Point Defect. Studies in Inorganic Chemistry 21, Luminescence and the Solid State, 2nd Edition, Elsevier, 138 Mountain Avenue, 2004, pp. 39-112.

[21]. Matsuzawa T.; Nabae T.; Katsumata T.; Sasajima K. J. Electrochem. Soc. 1997, 144, L243-L245.

[22]. Lin Y.; Tang Z.; Zhang Z.; Nan C. W. Appl. Phys. Lett., 2002, 81, 996-998.

[23]. McKeever S.W. S. Thermoluminescence Analysis. Thermoluminescence of Solids, Cambridge Solid State Science Series, Cambridge University Press, New York, 1985, pp.64-122.

[24]. Horowitz Y. S.; Yossian D. Radiat. Protect. Dosim. 1995, 60, 1-114.

[25]. Misra S. K.; Eddy N. W. Nucl. Inst. Meth. 1979, 166, 537-540.

[26]. Chen R. J. Electrochem. Soc. 1969, 116, 1254-1257 (1969).

[27]. Jahan M. S.; Cooke D. W.; Hults W. H.; Bennett J. L.; Maez M. A. J. Lumin., 1990, 47, 85-91.

[28]. Sakai R.; Katsumata T.; Kumuro S. J. Lumin, 1999, 85, 149-154.

[29]. Dorenbos P. J. Lumin. 2007, 315, 122-123. 